\title{
A Imagina(organiza)ção surrealista: rompendo a gaiola de ferro dos estudos organizacionais
}

\author{
The surrealist imagina(organiza)tion: breaking the iron cage of organization \\ studies
}

Alexandre Reis Rosa'

\begin{abstract}
“O sonho não é o contrário da realidade. Ele é um aspecto real da vida humana, assim como a ação; e um e outra, bem longe de se excluírem, se completam. Mas, este aspecto, negligenciado ou voluntariamente relegado ao plano das superstições perigosas pela civilização atual (a das casernas, das igrejas e das delegacias) contém os fermentos de revolta mais violentos por serem os mais profundamente humanos".
\end{abstract}

Jean Schuster (1990, p. 45).

\begin{abstract}
Resumo
Neste artigo apresento uma interface entre arte e administração, tendo o movimento surrealista como ponte de conversação entre as duas áreas. Em virtude da dinâmica dos estudos organizacionais no Brasil e de sua dependência teórica com o mundo anglo-saxão, o pensamento subversivo e libertário subjacente à arte surrealista pode ser explorado como instrumento de ruptura das grades simbólicas que aprisionam nossa criatividade na gaiola de ferro dos estudos organizacionais. Nesse sentido, o objetivo no trabalho é analisar o contexto atual a partir de três cenas: uma instável, que retrata a ruptura dos anos 1920 com a proposta de autonomia do movimento surrealista; uma estável, com a fixação do fenômeno organizacional em paradigmas e sua travestida evolução expressa pelo domesticado movimento do Critical Management Studies (CMS). Outro ponto está em analisar as possibilidades de ruptura a partir de uma nova cena onde estabilidade e instabilidade fazem parte de uma mesma realidade e deslocam o centro dos debates para o nosso próprio contexto, a fim de atingir a autonomia necessária para uma teorização organizacional brasileira com a mesma ousadia e criatividade dos precursores da aventura surrealista.
\end{abstract}

Palavras-chave: Surrealismo, estudos críticos em administração, produção acadêmica.

\begin{abstract}
In this paper I present an interface between art and management using the surrealist movement as point of intersection between the two areas. Considering the dynamics of the organization studies field in Brazil and its theoretical dependence in relation to the Anglo-Saxon world, the subversive and freedom thought underlying to the surrealist art can be explored as tool of rupture of the symbolic gratings that imprison our creativity in the iron cage of the organization studies. In this way, the objective of this paper is analyzing the current context from three scenes: an unstable one that portray the rupture on years 1920 with the proposal of autonomy of the surrealist movement; a stable one with the setting of the organization phenomenon in paradigms and its hidden evolution express for the domesticated movement of Critical Management Studies (CMS); and analyzing the possibilities of rupture from a new scene where stability and instability are part of the same reality and transfer the center of the debates for our own context in order to reach the necessary autonomy for the Brazilian organization theorization with the same boldness and creativity of the surrealist adventure precursors.
\end{abstract}

Key words: surrealism, critical management studies, academic issue.

\footnotetext{
1 Mestre em Administração pelo Pós-Graduação em Administração da Universidade Fedral de Lavras (PGA-UFLA e Doutorando pela Fundação Getulio Vargas Escola de Administração de São Paulo (FGV/EAESP). Endereço: Rua Guacuris, 34, Apto 151, 04321-080, São Paulo - SP - Brasil. E-mail:
} alexandrereisrosa@hotmail.com .

Artigo recebido em novembro de 2006 e aceito para publicação em março de 2007 


\section{Introdução: sobre Arte e Administração}

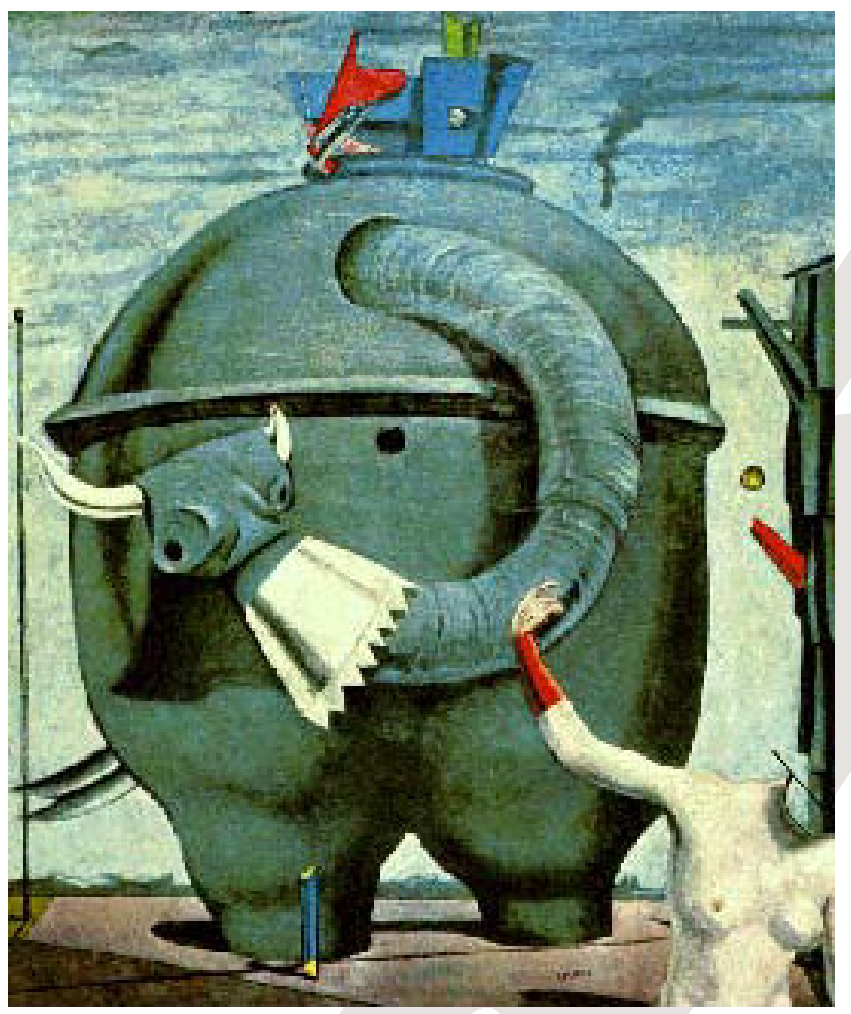

o Elefante Celebén

Max Ernst

A metáfora do elefante da administração formulada com base no antigo conto Hindu, em que seis cegos - cada qual apalpando uma parte distinta do elefante - tentam compreender a natureza do animal, nos passa a idéia da dificuldade de se compreender um fenômeno a partir de apenas uma de suas partes. Utilizando a mesma metáfora, Morgan (1986) acrescenta a hipótese de o elefante começar a se mover, dificultando ainda mais a apreensão de sua forma geral. O objetivo da utilização da referida metáfora, aqui, portanto, é demonstrar que, assim como o elefante, a organização também não pode ser apreendida apenas por meio de uma de suas partes, assim como o fato de ser dinâmica ao invés de estática mostra que o todo organizacional é muito maior e mais complexo de ser compreendido do que se pensa. Agora imaginemos se o mesmo elefante fosse representado surrealisticamente, como na pintura de Max Ernst, em que são acrescentados novos elementos que visam a desestabilizar a imagem convencional que todos nós temos do referido animal. O que os cegos concluiriam a partir dela? Certamente ficariam ainda mais perplexos pelo fato de a nova representação ser bem diferente do que se tem em mente a respeito de elefantes. E quanto a nós que possuímos a capacidade de visualizar o todo num só relance, o que pensaríamos a respeito do elefante celebén? Seriamos capazes de compreendê-lo a partir de nossas pré-concepções do que seja um elefante? É possível que não...

No quadro de Ernst, o imenso "elefante" se depara com um manequim feminino nu e sem cabeça, que acena com a mão para o alto como se indicasse ao animal o caminho a ser seguido. $\mathrm{O}$ animal ostenta dois chifres na cabeça, mas atrás dele aparecem duas presas que sugerem a existência de uma segunda cabeça alternativa. À direita da foto e um pouco atrás dele, aparece uma árvore cujo galho tem o mesmo formato do bracelete vermelho do manequim, sugerindo um outro braço que indica à suposta segunda cabeça um outro caminho a ser seguido. O elefante, a árvore e o(s) manequim(ns) estão em terra firme, mas há peixes no céu, as pistas na tela parecem mais confundir do que ajudar o espectador na busca de um significado. $\mathrm{O}$ animal em si e o(s) manequim(ns) que compõem o quadro não tiveram origem na mente de Ernst, pois "[...] já existiam no mundo exterior e, portanto, uma vez 'reconhecidos' pelo artista como uma imagem potencialmente válida, poderia ser apropriado e reelaborado pela imaginação do artista" (BRADLEY, 1999, p. 28, grifo nosso). 
Nesse sentido, como afirma Gombrich (1979, p. 4), "uma coisa que realmente não existe é aquilo a que se dá o nome de Arte. Existem somente artistas". Em outros tempos, eram aqueles homens que pintavam animais em cavernas. Hoje são aqueles que usam computação gráfica e reproduzem suas obras infinitamente. No entanto, em ambos os casos, existe o mesmo esforço do artista em retratar uma imagem que ele julga ser a expressão daquela realidade. Por outro lado, a classificação destas expressões denominou-se de Arte. Ou seja, uma forma mais precisa de se delimitar uma prática possuidora de determinados pressupostos que representam um estilo, uma época e uma visão de mundo que nos ajuda a apreendê-la segundo seu contexto de produção. Todavia, se perguntássemos ao surrealista Max Ernst por que ele pintou um "elefante céleben" de forma tão diferente ao que convencionalmente conhecemos a respeito do animal na tela, dificilmente ele daria uma resposta tão convincente a ponto de modificar nossas pré-noções do que seja um elefante.

De forma análoga, penso na possibilidade de inferir sobre a inexistência do que se chama de Administração. Existem somente administradores. Outrora, eram aqueles homens que organizavam suas aldeias e dividiam as tarefas entre homens e mulheres e se preparavam para a guerra e para o inverno. Hoje, são aqueles que organizam a produção dividindo as tarefas entre pessoas e máquinas e se preparam para as flutuações de mercado e para as políticas governamentais. No entanto, aqui também existe um ponto de convergência entre as duas situações: o esforço do administrador em organizar da forma que ele julga mais eficiente e eficaz aquela realidade. Assim, à classificação destas formas de organizar se deu o nome de administração. Isto é, uma forma mais precisa de se delimitar uma prática que também possui seus pressupostos e - igualmente à arte representa um estilo, uma época e uma visão de mundo que nos ajuda a compreendê-la segundo seu contexto de produção. Mas se perguntássemos a um administrador por que ele organizou aquela realidade de uma forma e não de outra, talvez ele até nos desse uma explicação "racional" para os processos envolvidos, mas possivelmente não seria tão convincente ao ponto de modificar nossas pré-noções do que seja uma organização.

Em ambos os casos, tanto da forma de expressar como de organizar, não é fácil nos libertarmos de nossos preconceitos do que seja uma coisa ou outra. Assim, tendemos a ser ineficientes na apreensão das razões por trás deles. Até mesmo os próprios agentes de produção do sentido da arte e da administração muitas vezes também estão condicionados aos pressupostos inerentes aos seus respectivos contextos de produção e tendem a reproduzir práticas que são institucionalizadas pelo hábito (BERGER; LUCKMANN, 1989). No entanto, em se tratando da Arte, os melhores artistas são aqueles que têm a enorme capacidade de se libertar de idéias préconcebidas e produzir imagens que nos levem a ver na realidade contornos de cuja existência nunca havíamos sonhado. De maneira que somos conduzidos, mesmo que de relance, a ver o mundo fora da nossa própria janela e entender que existem múltiplas formas de se expressar o que seja um elefante ou, por extensão, o que seja uma organização. Com efeito, não existe maior obstáculo à fruição de uma obra do que a nossa relutância em descartar hábitos e preconceitos (GOMBRICH, 1979).

A partir desta perspectiva, penso que a possibilidade de enxergar outras formas de organizar (MISOCZKY; VECCHIO, 2004) passa necessariamente pela adoção de um pensamento libertário e subversivo. Assim, a proposta neste artigo é explorar as interfaces entre Arte e Administração, tendo o movimento surrealista como principal ponte de conversação entre as duas áreas. Dado que a dinâmica particular do campo dos estudos organizacionais no Brasil e a sua declarada dependência teórica com o mundo anglo-saxão, reproduzindo suas virtudes e deficiências através de uma histórica relação de dominação entre centro e periferia na produção acadêmica (RODRIGUES; CARRIERI, 2001; VIEIRA; CALDAS, 2005), o pensamento artístico, em particular o surrealista, pode ser um interessante instrumento de ruptura das grades simbólicas que aprisionam nossa criatividade nos grilhões da gaiola de ferro dos estudos organizacionais.

A interface entre as duas áreas do conhecimento tem sido alvo de diversos estudos no campo da Administração (ver BÖHM, 2001; CARR, 2002; ATKINSON, 2004), e o Surrealismo, em particular, aparece na análise feita por Carr e Zanetti (2000), que utilizaram os pressupostos do referido movimento como forma de compreender a emergência de alguns trabalhos pós-modernos/pós-estruturalistas no âmbito dos estudos organizacionais, que adentram os domínios e aplicam as técnicas de produção surrealista. Também o trabalho de Wood Jr. (2001) estabelece uma relação do simbolismo organizacional com a (re)introdução da imaginação simbólica feita pelos surrealistas no início do século XX. Minha análise, por sua vez, explora o componente político do movimento e busca compreender o contexto atual de produção no campo dos estudos organizacionais a partir de uma 
articulação entre imagem e texto, numa dialética entre arte e organização, com vistas a alargar nossa percepção sobre esta última e principalmente: instigar o leitor a desconstruir algumas prenoções do que seja o ato de organizar.

Nesse sentido, meu objetivo é o de analisar nosso contexto atual de produção a partir de um texto elaborado em três cenas: uma cena instável que retrata a ruptura artística dos anos 1920 com a proposta de autonomia do movimento surrealista e seu viés político - o que ajudou a perpetuar seu legado -; outra estável, com a fixação do fenômeno organizacional em paradigmas burocráticos de análise e a sua travestida evolução expressa pelo cínico e domesticado movimento do Critical Management Studies (CMS). E, finalmente, analisar as possibilidades de ruptura a partir do rompimento com o status quo - aqui denominado de gaiola de ferro dos estudos organizacionais - e propor uma nova cena onde estabilidade e instabilidade fazem parte de uma mesma realidade. Assim, se desloca o centro dos debates para o nosso próprio contexto, a fim de valorizar a nossa produção crítica, cuja teorização compartilha de muitos pressupostos defendidos pelo Surrealismo. E, desse modo, se busca uma autonomia que possibilite desenvolver uma teorização organizacional brasileira com a mesma ousadia, subversão e criatividade dos precursores do movimento surrealista.

O texto, portanto, está estruturado com base nestes movimentos: instabilidade, estabilidade, ruptura e inovação. Este formato em quatro atos, por conseguinte, não segue uma lógica convencional de artigos acadêmicos. O racionalismo, o logicismo e a linearidade previstos neste tipo de trabalho não são contemplados de forma plena, e o resultado obtido tampouco é uma contribuição científica. Isto porque, se estamos trabalhando no limiar entre as áreas de arte e administração, me disponho aqui a não estar preso a esta última, com suas regras e formas especificamente racionais e normativas de produção. Aliás, isso seria até um contra-senso para um escriba que se dispõe a falar do movimento surrealista! Embora reconheça a dificuldade de me desvincular totalmente de tais regras, em virtude de já compartilhar de seus pressupostos, meu esforço será o de assimilar e, na medida do possível, expressar a liberdade proposta pela arte surrealista, em contraponto ao insulamento burocrático dos estudos organizacionais, e com isso extrair algum substrato que possa, num exercício dialético, nos elevar a um estado superior que possibilite superar sem suprimir as contribuições de ambas as áreas do conhecimento. 


\section{A cena instável: o legado surrealista}

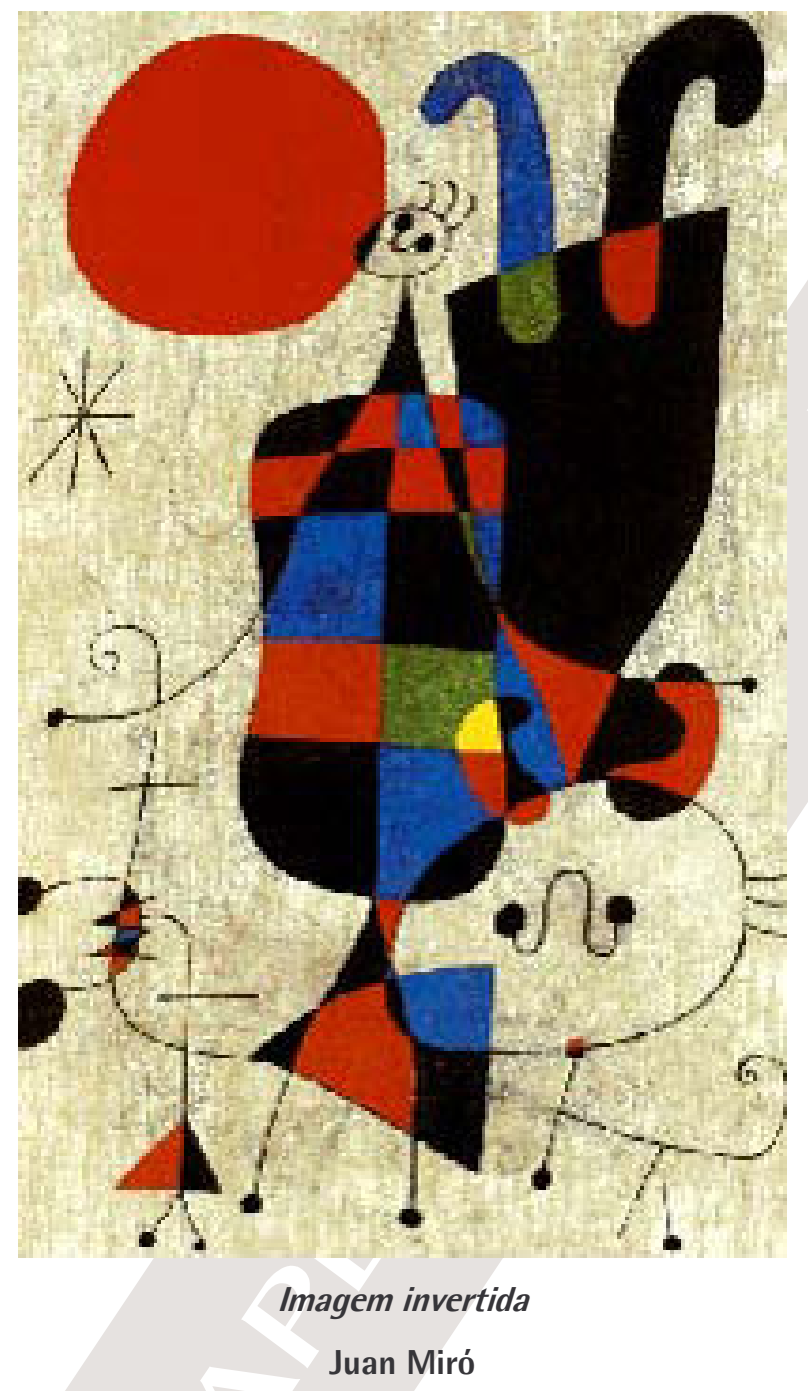

Trabalhando em ateliês contíguos, cuja proximidade era potencializada por um furo na parede divisória, os pintores Juan Miró e André Masson tiveram certo dia uma conversa que mudaria definitivamente os rumos da pintura contemporânea. Na ocasião, Miró perguntou a Masson: "Vale mais a pena ir conhecer Picabia ou Breton?" ao que respondeu categoricamente: "Picabia já era. O futuro é Breton!" A partir daí acontece o encontro do poeta André Breton com Miró, resultando numa alavancagem do que se conhece hoje por movimento surrealista, cujo início se deu na literatura e depois ganhou fôlego nas artes plásticas, em particular na pintura, com a vigorosa contribuição de Miró - que logo se identificou com a proposta revolucionária do movimento de inverter a lógica vigente e explorar novos métodos para a arte e para a vida, num intenso esforço de alargar a percepção desta última -, seguindo posteriormente para o teatro, cinema, a arquitetura e filosofia (BRADLEY, 1999).

No entanto, a ênfase de Masson acerca da derrocada de Francis Picabia é injusta - considerando a contribuição que o movimento dadaísta deu à emergência do Surrealismo liderado por André Breton. De acordo com Bradley (1999), o movimento Dadá tem sua gênese quando o escritor Hugo Ball inaugura em Zurique o Cabaré Voltaire, em 1916. Foi neste espaço que os primeiros encontros do grupo dadaísta ocorreram, e nomes como Tristan Tzara, Marcel Janco, Jean Arp e Richard Huelsenbeck animavam as discussões em torno de um novo embasamento, não racional, para as artes, e de uma crítica sistemática à racionalização, divisão e especialização mediante as quais se pretendia simplificar a vida moderna e torná-la mais estável. No mesmo ano lançam a Revista Dadá - cuja proposta era inverter todas as concepções e hierarquias artísticas e estéticas presentes na 
tradição de arte agradável, executada no respeito acrítico das regras acadêmicas - e transcendem suas fronteiras originais alcançando outros movimentos de natureza similar que eclodiam em Nova York, com Alfred Stieglitz; em Colônia, com Max Ernst; e em Paris, com Marcel Duchamp e Francis Picabia. Em 1918, o movimento publica o manifesto dadaísta declarando que o Dadá "[...] era um modo de ser, e o melhor palco para o dadaísta era a vida, mas os principais adereços necessários à encenação nesse palco permaneciam sendo a poesia e a arte" (BRADLEY, 1999, p. 16). Com a temporada Dadá organizada em Paris por Tzara e Picabia, em 1920, o movimento ganha o entusiasmo de André Breton, que de início se identifica com a explosiva proposta de ruptura apresentada pelos dadaístas e como duas ondas quebrando uma na outra, dadaísmo e surrealismo coexistiram durante algum tempo num fluxo contínuo de troca de estímulos e energias, até o rompimento de Breton com Tzara, em 1921.

Embora os dadaístas tivessem uma proposta original de uma nova concepção artística, o niilismo do movimento era muito eficiente para destruir todas as convenções, mas incapaz de propor algo construtivo. Desse modo, os surrealistas concluíram que o manifesto dadaísta de 1918 escancarava muitas portas, mas nenhuma delas levava a algum lugar. Assim, diante da deliberada negatividade Dadá, o grupo surrealista se separa dos dadaístas e delineia um projeto próprio.

Assim, foi com a eloqüente afirmação de que "não é por medo da loucura que vamos hastear a bandeira da criatividade a meio mastro", que o poeta francês André Breton $(1985$, p.8) e seus colaboradores registraram suas intenções no primeiro manifesto surrealista assinado em 1924. A idéia do grupo era fundar um movimento artístico - tal qual o Dadá - que não estivesse aprisionado aos ditames da arte convencional, mas que pudesse propor alternativas de produção artística. Ou seja, novas formas de produção artística que fossem livres e automáticas - para além das convenções que "alguém" outrora delimitou. Segundo Breton e seus companheiros - inicialmente influenciados pela psicanálise freudiana -, para liberar a criatividade, seria necessário um ato criador que não tivesse a influência do superego, para tanto, isso seria feito por meio do que ele chamou de automatismo psíquico.

A idéia de liberdade era a viga mestra do movimento, que rapidamente ganhou forte conotação política e tratou de se aproximar inicialmente da crítica marxista como forma de adensar os debates e expressar seus objetivos emancipadores (LÖWY, 2002), seguindo-se uma aproximação com o anarquismo como forma de absorver seu caráter subversivo. Assim, na junção das duas tradições, buscava-se promover um mundo libertário que, para o movimento, resumia-se num mundo surrealista (COELHO, 1990).

Um dos legados mais importantes do surrealismo foram as técnicas de criação artística desenvolvidas pelo grupo, entre as quais se destacam o automatismo, o trope-l'oiel ou fixação de imagens dos sonhos e a negação da representação (CATTANI, 1991). O automatismo psíquico marcou a primeira fase do surrealismo e foi o grande influenciador dos primeiros trabalhos artísticos produzidos pelo grupo. Sua utilização pelos surrealistas ocorreu a partir da ruptura com o Dadá e se caracterizou por uma fase de experimentalismo denominada de "temporada dos sonos", cuja essência era a principal marca do movimento. O estado de transe, segundo Breton, era o principal caminho de acesso ao maravilhoso, isto é, os momentos oníricos da mente possibilitavam extrair imagens diretamente do inconsciente, sem qualquer controle da razão. Desse modo, os surrealistas se encontravam em cafés ou em suas casas e ateliês para escrever e falar em estado de transe. A poesia foi a maior beneficiada do automatismo, uma vez que só dependia de uma idéia e um pedaço de papel. Já a pintura, em virtude do processo complexo de criação das telas, teve de se adaptar e desenvolver métodos próprios para alcançar o maravilhoso via automatismo. Nesse sentido, André Masson cria a técnica de pintura com areia, Max Ernst desenvolve as técnicas de colagem, frottage (esfrega) e grattage (raspagem), e o espanhol Miró um dos mais prodigiosos entre os pintores surrealistas, segundo Pierre (1991) - desenvolve uma fusão entre "[...] automatismo verbal e visual com tipos compatíveis de comunicação não racional" (BRADLEY, 1999, p.25).

Num segundo momento de produção artística do movimento surrealista, foram desenvolvidas as técnicas do trope-l'oiel, em que se destacam os trabalhos desenvolvidos por Salvador Dalí, que se valia do método de paranóia crítica criado por ele mesmo, ou seja, um tipo de sistema acadêmico consciente de representação para traduzir as imagens oníricas produzidas numa espécie de excitação imaginativa mantida pelo pintor. Tratava-se 
de transferir para a tela fragmentos de sonhos e dar-lhes um efeito de inquietante estranheza baseada na interpretação dos próprios sonhos, dentro de uma lógica freudiana marcada pela substituição, condensação, deslocamento e simbolização.

Outro caminho para a produção surrealista foi o da crítica à tradição representativa, cujos trabalhos mais significativos foram as telas produzidas por René Magritte, que trazem um misto de racionalidade e ironia. Segundo Magritte, os "mistérios do mundo" são bem mais amplos do que as imagens dos sonhos, pois jogam com vários níveis de conhecimento da realidade. Assim, para captar tais mistérios era preciso estar bem acordado, porém sem perder de vista o caráter "surreal" de toda e qualquer imagem, pois tomar a arte como janela aberta para o mundo era alimentar a ilusão de que a imagem pudesse substituir o objeto. Ademais, para Magritte, não havia qualquer possibilidade de relação real entre arte e as coisas do mundo (CATTANI, 1991).

Embora o Surrealismo tenha tido sua gênese nas artes, definitivamente não se limitou a elas. A liberdade da criação artística expandiu-se para além dos ateliês e cafés e ganhou espaço nos debates políticos de sua época. A ambição de restituir ao indivíduo os poderes de que foi despojado por certas forças e certas instituições muitas vezes com a sua própria cumplicidade - levou o movimento a buscar um tipo de liberdade concreta, exeqüível no plano social (SCHUSTER, 1991).

Assim, no segundo manifesto surrealista de 1930, os surrealistas aderem ao materialismo histórico e ao comunismo por meio de sua afiliação ao Partido Comunista Francês (PCF). No entanto, como observa Löwy (2002), o alinhamento de Breton e seus colaboradores à crítica marxista deu-se de forma muito peculiar. Ou seja, sem perder de vista a necessidade imperiosa de combater a ordem burguesa, eles defendem um tipo de marxismo romântico, tal qual Walter Benjamin, Ernest Bloch, Herbert Marcuse e outros. Trata-se de uma corrente subterrânea que atravessa o século XX acima das barragens ortodoxas impostas pela "[...] tendência racionalista/cientificista, cartesiano/positivista, fortemente marcada pelo materialismo francês do século XVIII - que dominava a doutrina oficial do comunismo francês" (LÖWY, 2002, p. 33). O marxismo surrealista era uma forma de pensamento fascinada por certas formas culturais do passado pré-capitalista, tinha por objetivo rejeitar a racionalidade fria e abstrata da civilização industrial moderna e, por meio da imaginação, promover a tentativa romântica/revolucionaria de re-encantar o mundo resgatando a dimensão simbólica e inconsciente da natureza humana.

Ainda no rastro da liberdade e diante do socialismo real conduzido de forma oportunista e totalitária por Stalin, o movimento surrealista rompe com o PCF e retoma os escritos do primeiro manifesto de 1924, se (re)aproximando do pensamento anarquista. Afinal, como o próprio André Breton afirmou em uma de suas cartas publicadas no jornal Le libertaire - órgão da Federação Anarquista Francesa -, "foi no negro espelho do anarquismo que o surrealismo se reconheceu pela primeira vez, bem antes de se definir a si mesmo e quando era apenas associação livre de indivíduos, rejeitando espontaneamente e em bloco as opressões sociais e morais do seu tempo" (BRETON, 1990, p. 41).

Outro evento importante que contribuiu para a aproximação do Surrealismo com o movimento anarquista foi o encontro de Breton com Trotski, no México, em 1938. Neste encontro eles redigem um dos documentos mais importantes da cultura revolucionária: Por uma arte revolucionária independente, cujas intenções podem ser resumidas na passagem na qual afirmam que "[...] para a criação cultural a revolução deve, desde o começo, estabelecer a assegurar um regime anarquista de liberdade individual. Nenhuma autoridade, nenhuma coerção, nenhum traço de comando! Os marxistas podem, aqui, marchar de mãos dadas com os anarquistas" (BRETON e TROTSKI apud LÖWY, 2002, p. 34).

Além de citar o regime anarquista como condição sine qua non para a liberdade individual, a passagem expressa também o desejo de uma fusão entre marxismo e anarquismo. Ou seja, decepcionados com os desdobramentos do marxismo stalinista, mas adeptos do marxismo romântico e, ao mesmo tempo, ávidos por uma liberdade incondicional, os surrealistas colocavam-se diante de um paradoxo: como conciliar a negatividade anarquista com a ação disciplinada do marxismo? Como conciliar a revolução do espírito com a revolução social? Afinal, como afirma Schuster (1990, p. 103), “[...] tudo está ligado, ao capitalismo do dinheiro corresponde o capitalismo do pensamento, e seria inútil querer destruir um conservando o outro 
intacto". A solução encontrada pelo movimento foi seguir a linha de orientação inscrita na própria essência do movimento: superar as oposições estáticas presentes por muito tempo no teatro de sombras da cultura, tais como matéria/espírito, racionalidade/irracionalidade, vigília/sonho etc. Ou seja, assumir a noção hegeliana de Aufhebung, que traz consigo o movimento dialético de negação/conservação e sua superação em direção a um nível superior (LÖWY, 2002; SCHUSTER, 1990), e assim preservar, num só foco, as luzes vermelha e negra que iluminam profanamente a utopia revolucionária de um outro movimento, livre e harmônico, de uma civilização apaixonada (AHRENS, 2001).

A dimensão política do movimento surrealista teve, como resultado prático, portanto, a denúncia e o combate a todas as opressões presentes na sociedade contemporânea, tais como a opressão econômica dos trabalhadores pelos patrões, da mulher pelo homem, do filho pelos pais, do homem negro pelo homem branco, do cidadão pelo burocrata, etc. E, ainda, no plano macrosocial, todo e qualquer movimento de dominação colonialista, tal qual o que foi mantido durante séculos - e de certa forma continua no plano cultural - pela França e pela GrãBretanha junto às nações periféricas. Todavia, esse conjunto de opressões tem como pano de fundo um sistema de pensamento dominante em nossa sociedade: o racionalismo, cuja força "[...] abafa a voz poética, promulgando a superioridade do consciente sobre o inconsciente, da linguagem utilitária sobre a linguagem lírica, do ato finalista sobre o ato desinteressado, da lógica formal sobre a magia" (SCHUSTER, 1990, p. 32). Aprisionava, assim, a percepção do mundo numa representação linear ou plana, da qual é deliberadamente excluída a dimensão simbólica, ou como denominou Max Weber: uma verdadeira gaiola de ferro.

Finalmente, retomando a dimensão artística do movimento, vale ressaltar que os pressupostos surrealistas espraiaram-se por diversos campos da produção cultural. Sua influência se fez notar não apenas na literatura e nas artes plásticas, conforme enfatizei nesta seção, mas ganhou espaço também no teatro com o dramaturgo Antonin Artaud e seu teatro da crueldade, que buscava livrar o espectador das regras impostas pela civilização e assim despertar-lhe o inconsciente por meio da união entre palco e platéia. No cinema, Luiz Bruñuel faz uma revisão dos cânones visuais e materializa a noção de humor negro que está na base da estética surrealista. Enquanto movimento artístico e político, o Surrealismo não existe mais. Porém, se tomarmos sua histórica convicção de que não se pode viver como um ser humano digno desse nome sem combater com pertinácia e vontade inabalável a ordem estabelecida, poderemos, então, afirmar que o surrealismo ainda está entre nós e só desaparecerá "[...] quando o homem não tiver outro limite para sua liberdade a não ser a fadiga de seus desejos" (SCHUSTER, 1991, p. 37). Ou seja, o espírito surrealista ainda tem alguns milênios pela frente. 


\section{A cena estável: o legado do maistream}

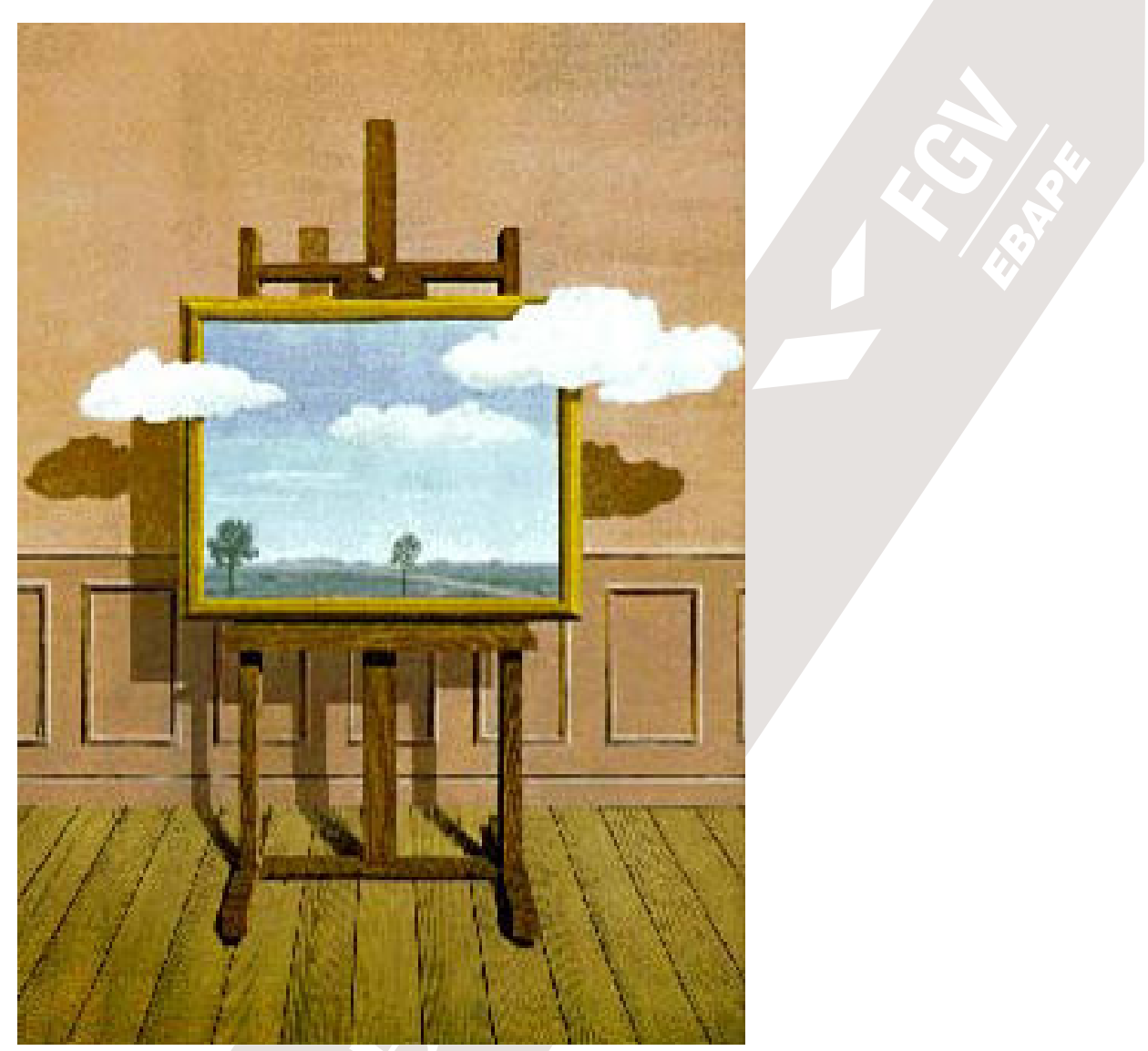

$A$ vingança

René Magritte

Em outra direção, antagônica ao movimento de 1924, acontecia o movimento que caracterizou a chamada "cena estável" dos estudos organizacionais. Nela, dois autores anglo-saxões davam conta de aprisionar o conhecimento organizacional num esquema geométrico chamado de "paradigmas sociológicos de análise organizacional". Segundo Gibson Burrel (1999), um dos autores da façanha, o objetivo de esquematizar diversas tradições teóricas em paradigmas era justamente o contrário. A expectativa era romper com a ortodoxia e proporcionar uma espécie de "abertura da caixa de pandora" e, nesse sentido, apresentar outras formas de se pensar a organização. No entanto, a empreitada obteve um resultado ambíguo: se de um lado trouxe à tona a riqueza paradigmática e as inúmeras possibilidades de cada tradição teórica, de outro enclausurou estas tradições ao anunciar a falácia da incomensurabilidade. $\mathrm{O}$ efeito disso foi uma estabilização da cena. Ou seja, encerrar toda pluralidade paradigmática num quadro tal qual a pintura apresentada por René Magritte, na qual a realidade do mundo cabe na moldura de um quadro. Mas com um detalhe: os sonhos ou a imaginação, representados pelas nuvens, transcendem este espaço e são, por sua vez, impossíveis de compor a pretensa cena.

A crítica de Magritte ao realismo, conforme demonstrei no item anterior, enfatizava a impossibilidade de a imagem substituir o objeto. Assim, ao observarmos o quadro $A$ vingança, vemos que ele estrutura-se, à primeira vista, de forma tradicional: uma imagem interior composta por um trecho de parede e outro de assoalho. O assoalho é de tábuas, cujas linhas convergentes sugerem um espaço perspectivo. Sobre o mesmo, situa-se um cavalete que serve de suporte para uma tela, emoldurada, na qual está representada a imagem de um campo verde e um céu com nuvens. Se o quadro fosse apenas isso, seria facilmente identificado no estilo acadêmico de pintura. Mas um elemento insere uma forte perturbação: as nuvens pairando fora da moldura. A representação do quadro dentro do quadro sugere um desdobramento do lugar da imagem, ou seja, o quadro 
representa-se a si mesmo no quadro, a partir de uma técnica chamada de en abyme (em abismo). Trata-se de “[...] um jogo de representação consigo mesma e esse jogo é talvez contemporâneo das encenações da representação, pois se a representação tudo põe em cena, como não teria ela a insolência de se representar a si própria? O efeito de abismo é uma vertigem. O desdobramento da imagem, interno a essa mesma imagem, desdobra esse duplo primordial que é toda e qualquer imagem em relação ao seu exterior" (LE BOT apud CATTANI, 1991, p. 126).

Nesse sentido, ao apresentar uma realidade (campos verdes e nuvens) emoldurada dentro de outra moldura cuja apreensão é incompleta devido às nuvens arredias, Magritte sugere a ineficácia da representação e, com isso, revela o caráter "surreal" de toda e qualquer imagem. Voltando esta perspectiva para o caso do insulamento paradigmático de Burrel e Morgan (1979), temos que a pretensa incomensurabilidade defendida pelo modelo torna-se impraticável e a transcendência de suas próprias nuvens demonstra a incapacidade de representação do fenômeno. Com efeito, a "abertura da caixa de pandora" é que se torna o elemento incomensurável do modelo, pois as alternativas de teorização existentes se mostram impossíveis de serem dominadas a partir de um esquema geométrico, racional e, em certa medida, funcionalista. O caminho percorrido pela produção de teoria no campo organizacional nos mostra que tais nuvens jamais foram capturadas de fato e o que ocorreu na verdade, como tentarei demonstrar nos parágrafos seguintes, foi um esforço sistemático de escondê-las.

A seqüência dos fatos é conhecida: no início da década de 1980, logo após a publicação do modelo de Burrel e Morgan, acontece uma enxurrada de críticas sobre o trabalho e principalmente sobre a incomensurabilidade paradigmática. Funcionalistas rejeitam as alternativas, ao passo que os críticos as celebram. No entanto, ainda estava em aberto o problema da incomensurabilidade, pois as nuvens continuavam a pairar... Até que o próprio Morgan (1980) publica uma continuação do modelo paradigmático relacionando-o ao uso de metáforas como forma de se representar simbolicamente uma dada realidade e, por conseguinte, as escolas de pensamento adjacentes. Essa primeira abordagem das metáforas como recurso teórico foi aprofundada na publicação do famoso livro Imagens da Organização, cujo objetivo contrapôs a limitação da não-conversação paradigmática ao permitir uma livre compatibilidade entre as metáforas. Assim, Morgan (1986) faz uma dupla ruptura com seu trabalho anterior, na medida em que apresenta o livro numa forma não técnica, ou seja, em linguagem acessível tanto para acadêmicos como para profissionais, e desenvolve implicações práticas das metáforas na análise organizacional com sua "visão binocular" da realidade. Evidentemente, esta postura também foi sujeita a crítica, principalmente do seu ex-mestre e ex-parceiro do "sociological paradigms...", que o acusou de promiscuidade paradigmática e de vender a falsa idéia de que tradições teóricas poderiam ser combinadas como produtos em prateleiras de supermercado. Ao levantar tais questões, Burrel (1999) sinaliza que ainda não foi dessa vez que as nuvens puderam compor o quadro... E, assim, com vistas a explorar as alternativas para seus incomensuráveis paradigmas, Burrel se engaja no pós-modernismo e publica juntamente com Robert Cooper uma série de trabalhos que seria uma das bases para outro movimento de controle nuvioso: o Critical Management Studies (CMS).

Criada no início dos anos 1990, a partir de um esforço britânico de reunir diversas correntes críticas, a legenda "CMS" reflete uma série de mudanças no contexto político, econômico e social do Reino Unido, que movimentaram acadêmicos de diversas áreas das ciências sociais a se engajarem num projeto alternativo de teorização organizacional. Desse modo, o movimento de estudos críticos, segundo Fournier e Gray (2000), consolida o engajamento com o não-positivismo e com outros movimentos relacionados ao objetivo de expor as estruturas de controle, dominação e de desigualdades presentes no espaço organizacional, cujas dimensões estão ocultas nas teorias tradicionais. Para tanto, defendem uma posição que contemple uma visão desnaturalizada da administração, intenções desvinculadas da performance e um ideal de emancipação.

Nesta direção, Alvesson e Deetz (1999, p. 238) afirmam que os CMS estão voltados para a emancipação, pois buscam "[...] criar sociedades e lugares de trabalho livres de dominação em que todos os membros têm igual oportunidade para contribuir para a produção de sistemas que venham ao encontro das necessidades humanas e conduzam ao progressivo desenvolvimento de todos." Assim, observamos que as intenção do projeto britânico, a priori, contempla um ideal de liberdade para os viventes do mundo organizacional, com relações de poder mais simétricas e oportunidades de crescimento individual e coletivo. Dentro da nossa relação com os ideais surrealistas, podemos até dizer que contempla uma forma de ruptura com o mainstream instrumental da 
sociedade capitalista e com isso desestabiliza novamente a cena, liberando as nuvens de Magritte de serem aprisionadas no seio da racionalidade...

No entanto, Misoczky e Andrade (2005), de forma admiravelmente subversiva, problematizam esta premissa de emancipação defendida pela logomarca do CMS e ressaltam que na verdade trata-se de uma crítica domesticada, descomprometida com a condição emancipatória e com crescente legitimidade no seio do mainstream. Ou seja, usam o discurso da emancipação como mero exercício de retórica, pois estão mais alinhados com a manutenção do status quo do que com a ruptura em relação às concepções dominantes, que seria, a fortiori, a essência do pensamento crítico. Ademais, os CMS confirmam seu tempo-espaço como o contexto original de produção da crítica (FOURNIER e GREY, 2000), assumindo a posse de um novo mainstream em detrimento da tradição crítica existente em contextos de produção fora de suas fronteiras e, ainda, manipulando e subvertendo pressupostos epistemológicos e ontológicos de suas "afiliações" teóricas como forma de legitimar sua produção, sem qualquer compromisso com a ação transformadora inerente a elas, como é o caso do conceito de microemancipação organizacional de Alvesson e Willmott (1992), segundo o qual os autores acreditam realizar a emancipação nos limites da organização, sem que haja uma transformação no próprio sistema social (MISOCZKY e ANDRADE, 2005).

Com efeito, percebemos aqui um movimento de "harmonia administrativa" nos estudos organizacionais utilizando aqui o sentido atribuído por Tragtenberg (1980) sobre a estabilidade dos sistemas de gestão - durante sua evolução em contexto anglo-saxão. Na medida em que cada abordagem realiza um travestido movimento de desestabilização da cena, seguido da imediata estabilização por meio de um novo mainstream, fica evidente a manutenção de um monopólio teórico. Ou seja, em um esforço sistemático de representar o conhecimento organizacional tal qual a moldura de Magritte e, na impossibilidade de conter as nuvens, esconde-as utilizando um cínico expediente de manipulação teórica e de gerenciamento de impressões, ao delimitar - a seu modo - o que seja ou não a crítica.

Nesse sentido, Vieira e Caldas (2006, p. 67, grifo nosso) alertam que "[...] parece-nos imprescindível evitar a crítica dócil, que opera quase como uma nova 'gaiola de ferro', uma vez que tem origem em uma visão do norte sobre o sul ou, se o leitor preferir, centro sobre a periferia". Todavia, meu argumento aqui dispensa o "quase" em destaque na citação, pois se como demonstram Misoczky e Andrade (2005, p.224), "[...] a questão central não são as implicações éticas, políticas e sociais da gestão instrumental do trabalho, mas os crescentes custos deste modelo de gestão. Os autores [do CMS] se vestem de racionalidade instrumental para mostrar a necessidade de superá-la", então, estamos, sim, diante de uma nova gaiola de ferro que, entre outros motivos, aprisiona a crítica dentro de um monopólio teórico de domínio anglo-saxão, cujas grades e sua possível ruptura serão o tema do próximo item. 


\section{Rompendo a gaiola de ferro: a imagina(organiza)ção surrealista}

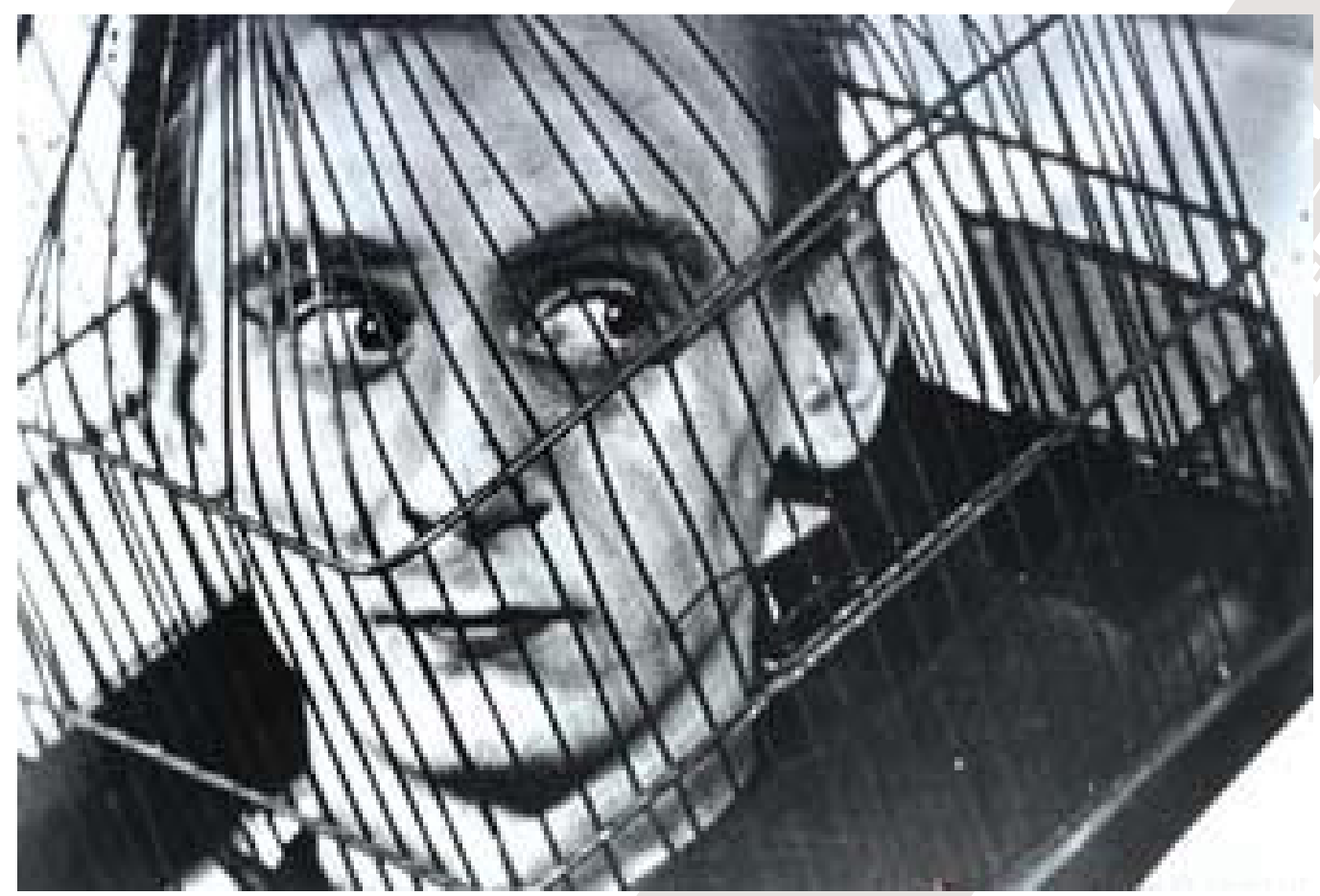

A gaiola

Sidney Peterson

A colagem apresentada no trabalho de Sidney Peterson representa uma forma de aprisionamento a que os indivíduos estão sujeitos nas sociedades modernas. Isto é, mesmo com a possibilidade de nos movermos de um lado para o outro, carregamos conosco uma gaiola que nos encerra e nos priva de uma plena autonomia. $\mathrm{O}$ olhar desconfiado mostra que alguma coisa está errada e ao mesmo tempo representa nosso desconforto diante do "inelutável". Em termos históricos, Peterson busca representar o movimento de racionalização e de intelectualização característicos da sociedade ocidental moderna, cujas conseqüências assinalam uma tendência à perda de liberdade, em função do crescimento da burocratização e sua alegação da previsibilidade do agir social dos indivíduos ou das estruturas sociais. Weber vai atribuir a este movimento de estabilização da cena a racionalidade formal que se transmuta numa "gaiola de ferro" - ou seja, uma estrutura reificada e alienada que encerra os indivíduos nas leis do sistema como em uma prisão - em que "[...] o saber científico toma lugar dos pressupostos religiosos, e o capitalismo moderno se sobrepõe a outras formas de organização social" (ARGÜELLO, 1999, p. 154). O pessimismo weberiano face aos destinos da razão pode ser entendido por meio das conseqüências de se ter um mundo administrado, perfeito, porém, sem alma e sem liberdade.

Ora, se vivemos hoje sob a égide da racionalização, cujas grades nos acompanham e nos aprisionam numa gaiola de ferro, desencantada, sem magia e sem alternativas para organizar a sociedade, ou mais especificamente presos ao movimento harmônico anglo-saxão da teoria organizacional e seu papel colonialista frente aos espaços periféricos de produção científica, então minha aposta aqui é a mesma defendida por Löwy (2002), de que o espírito surrealista é o martelo encantado que nos permite romper as grades para ter acesso à liberdade. Significa estar, como bem observa Benjamin (1980), na posição infinitamente perigosa entre a "subordinação anarquista e a disciplina revolucionária", ou seja, gozar dessa ambivalência política é priorizar o estado de liberdade que nos leva ao momento subversivo de estar à deriva. Isto é, não ter um destino certo, não calcular os fins, renunciar os modelos impostos, não ser mais prisioneiro do fetichismo da mercadoria e olhar as prateleiras de idéias sem se hipnotizar pelo brilho das embalagens, e, ainda, manter um olhar completamente alhures (LÖWY, 2002). A embriaguez do derivante, portanto, é a chave do pensamento herético, do pensamento crítico comprometido com a transformação, com a utopia de um mundo encantado onde as paixões humanas recuperem seu estado simbólico, mágico e revolucionário - onde o artista/administrador possa 
compreender as conseqüências da ação-racional-em-finalidade e com isso imaginar outras formas de expressar/organizar. Ao ler a coletânea de textos organizados por Silva e Marrach (2001), suponho que a teoria organizacional brasileira possua seu próprio derivante: Maurício Tragtenberg.

Com espírito avesso aos aspectos normativos da academia, Tragtenberg (1980) foi o responsável por uma das críticas mais agudas e originais sobre a burocracia no Brasil. Seu vigoroso trabalho expõe as origens e os desdobramentos de um modelo organizacional que alavancou o mundo administrado e teve sua legitimação com a consolidação das teorias administrativas e suas "harmonias", que possibilitaram e ainda possibilitam "[...] que o monopólio do poder continue intocado e que as relações de dominação continuem reduzindo as perspectivas de emancipação humana no mundo do trabalho" (PAULA, 2002, p. 78). Desse modo, Tragtenberg revela os expedientes utilizados pela burocracia enquanto sistema de dominação e nos mostra sua dinâmica de funcionamento no mundo contemporâneo, cujas grades se apresentam de forma cada vez mais sofisticadas, estabilizando a cena e furtando-nos de imaginar outras formas de organizar.

Contra este modo de pensamento único, Tragtenberg assume a posição de derivante e personifica - no âmbito dos estudos organizacionais - o espírito libertário defendido pelos surrealistas desde a sua gênese. Autodidata, Tragtenberg teve sua formação básica fora da normalização escolar, o que lhe garantiu uma forma original de ver o mundo, longe das mecânicas reproduções que os currículos escolares insistem em ensi(alie)nar. Tinha uma mente heterodoxa capaz de conciliar a gênese do racionalismo ocidental e suas conseqüências na burocracia weberiana, a ação revolucionaria do pensamento marxista e o espírito libertário do movimento anarquista. Dessa forma, Tragtenberg conseguia expressar a síntese tão sonhada pelos surrealistas de promover um tipo de "marxismo libertário" que pudesse superar sem suprimir o ideal de solidariedade e de liberdade de ambas as tradições. Ademais, eram justamente estes ideais que constituíam a base da interpretação tragtenberguiana.

Ora, diante das grades que aprisionam nossa criatividade e reduzem as opções de pensar em novas formas de organizar, Tragtenberg (1979) desfere sua crítica à delinqüência acadêmica e denuncia a gradativa subserviência dos intelectuais acadêmicos à dominação, produzindo sua "crítica domesticada" e, por meio da "pedantocracia", desqualificando o conhecimento que não esteja alinhado ao mainstream, ou melhor, ao tempoespaço outrora delimitado como o contexto "oficial" de sua produção. Pela via da relação entre $o$ saber $e o$ poder, denuncia também o colonialismo científico e sua pretensa imposição de "modas universitárias", ou logomarcas (tal qual o CMS) que representam o compromisso com a relação promíscua entre academia e mercado, gerando um fluxo e refluxo de recursos financeiros em troca de saberes instrumentais. Nesse contexto, a "pedagogia libertária" proposta por Tragtenberg (1979) seria o martelo encantado capaz de romper a gaiola e com isso liberar as nuvens da imagina(organiza)ção surrealista, na medida em que revela a contradição entre o sonho a ser realizado e a realidade que insiste em reforçar as grades da prisão instrumental. Ao defender uma prática intelectual feita pelo conflito em vez do consenso, Tragtenberg desestabiliza a cena de forma contundente, coloca a liberdade como elemento fundamental e nos dá o salvo-conduto de ver a universidade ser transformada em "multiversidade" vigiada pelos cães pastores da crítica! 


\section{Conclu(ilu)sões: por uma nova cena}

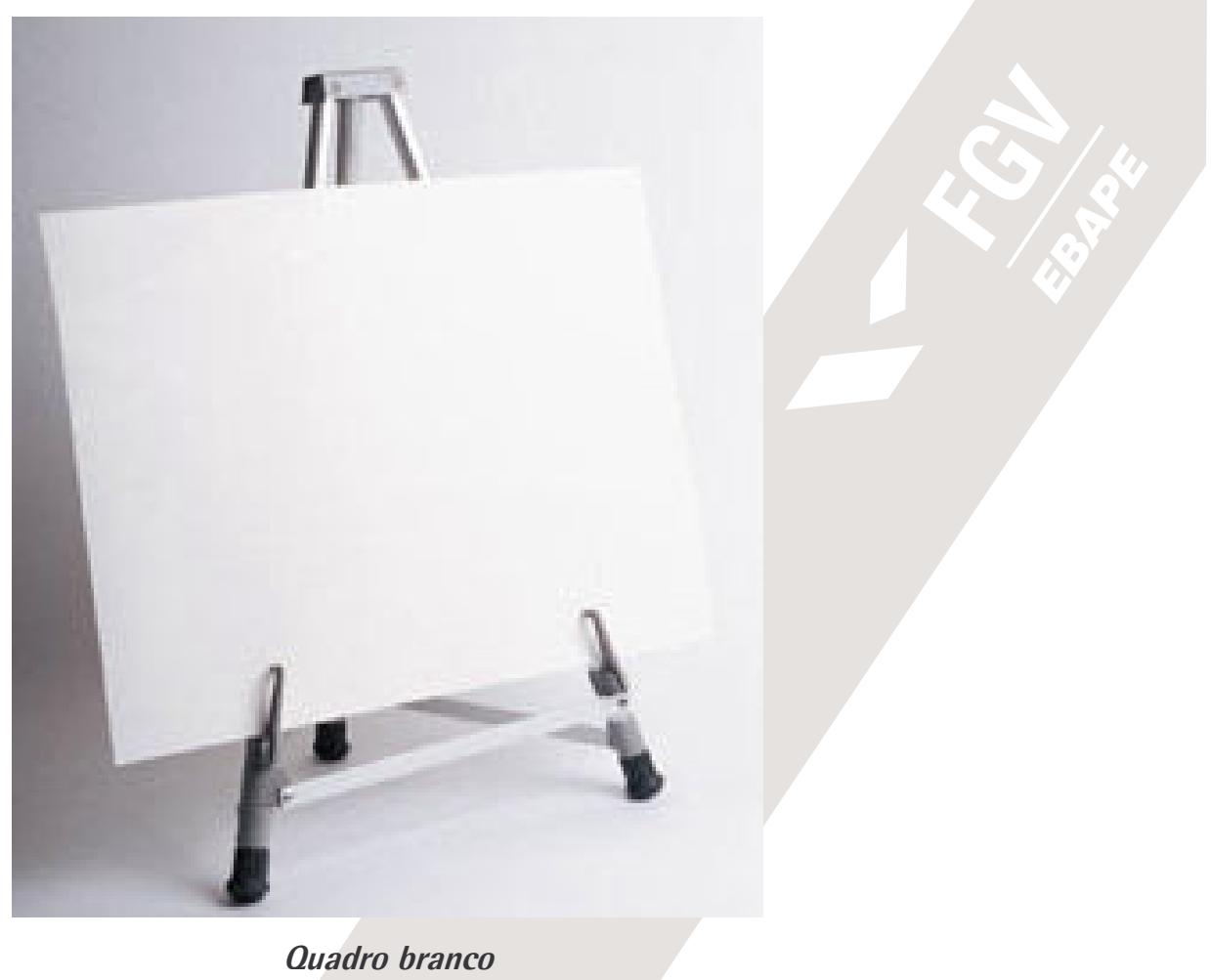

Se é que vivemos hoje, como afirma Robert Presthus (appud MOTTA, 1981), em uma "sociedade organizacional" cuja lógica vital inexiste fora dela, e a racionalidade predominante nestas organizações seria a de natureza instrumental, qual seria então o caminho mais acertado para imaginarmos uma nova cena? Qual é a tela em branco de que dispomos hoje para pensar uma outra forma de organizar a sociedade? Penso que diante desta configuração social e da cena aparentemente estável do mundo contemporâneo, os estudos organizacionais tendem a ser uma grande promessa a essa nova cena. Por outro lado, é também o principal ator que pode agravá-la sobremaneira. Daí a força do romantismo revolucionário do Surrealismo, com sua imperfeita, inacabada e quase utópica combinação entre pensamento libertário e ação revolucionaria, e da sua versão tragtenberguiana de pensamento heterodoxo e desestabilizador.

Finalmente, já que a narrativa foi conduzida em cenas e, como ressaltei na introdução, não estou preso às regras do campo científico, então não é necessária, aqui, uma conclusão daquelas em que você recupera os principais pontos do texto, destaca suas contribuições e por fim sugere uma articulação original frente ao tema apresentado. Prefiro tomar este espaço não como uma conclusão, mas como uma ilusão... E pensar numa nova cena a partir do dramaturgo surrealista Antonin Artaud e sua destruição da quarta parede no teatro, por meio da qual a encenação deixa de ser um fim em si mesmo e passa a contar com a contribuição dos espectadores (ou leitores, no nosso caso) que não estão mais fora da cena, pelo contrário, são parte dela. Penso que a emancipação do espectador é a precondição necessária para se ampliar a cena e dar a ela uma nova dinâmica, uma nova textura e uma nova gramática. Os espectadores estão tecnicamente fora, porque não ensaiaram e não leram o roteiro da peça, mas estão simbolicamente dentro, porque sem eles a própria cena não haveria razão de existir! Nos estudos organizacionais, por sua vez, enquanto existir a quarta parede, a cena estará estável e o artista/administrador estará aprisionado, sem qualquer chance de expressar/organizar a realidade de uma forma em que a liberdade seja vista como farol, tal qual a viam os precursores da aventura surrealista! 


\section{Referências bibliográficas: por detrás das cenas}

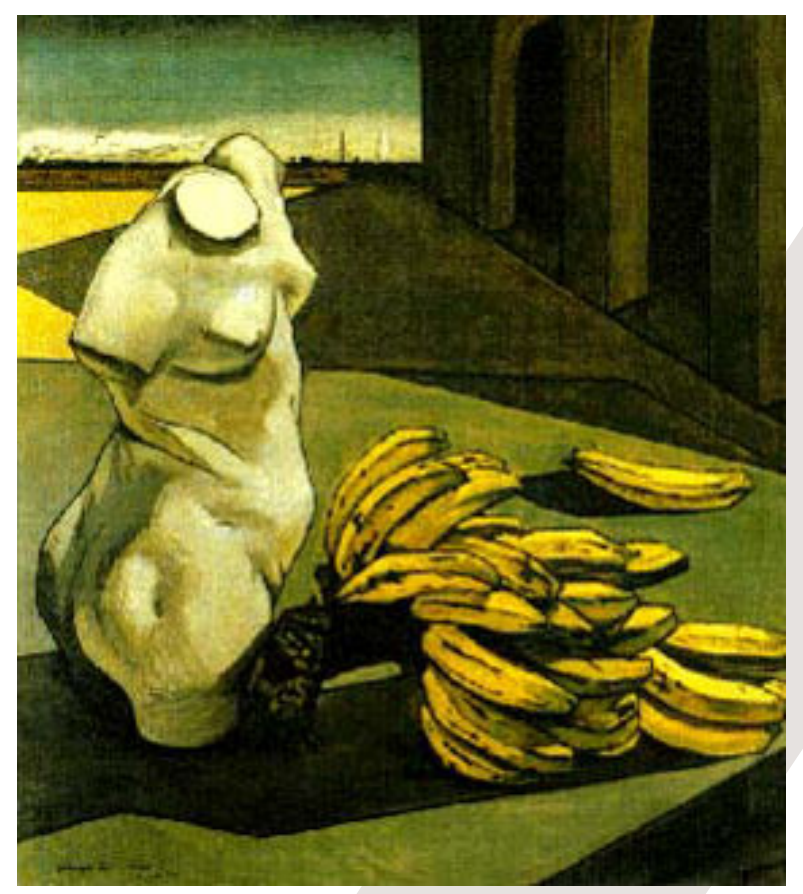

\section{A incerteza do poeta \\ Giorgio de Chirico}

Como afirmou Wright Mills (1972), em “A imaginação sociológica”, a produção acadêmica segue uma lógica artesanal na qual o artista - representado pela figura do autor - decide quais são os instrumentos que darão vida ao texto. Tais instrumentos são basicamente as referências bibliográficas escolhidas pelo autor, que sustentarão a idéia e formarão o corpo de argumentos defendidos por ele. Assim, a obra do pintor Giorgio de Chirico apresentada acima diz muito a respeito das escolhas, de muitas vezes ficarmos imóveis e incapazes diante das opções. Nas linhas abaixo, seguem a minha opção quanto aos instrumentos que viabilizaram a produção tropel'oiel deste texto, que não é artístico, não é cientifico e simplesmente não é... Está sendo!

AHRENS, G. et al. Surrealist subversion in everyday life. Socialist Review, v. 28, n.1, p. 170-205, 2001.

ALVESSON, M.; DEETZ, S. Teoria crítica e abordagens pós-modernas para estudos organizacionais. In: CLEGG, S. et. al. (Orgs.) Handbook de Estudos Organizacionais. v.1. São Paulo: Atlas, 1999.

ALVESSON, M.; WILLMOT, H. On the idea of emancipation in management and organization studies. Academy of Management Review, v.17, n.3, p.432-464, 1992.

ARGÜELLO, K. 0 mundo perfeito: nem possivel, nem desejável. In: SOUZA, J. (Org.). 0 malandro e o protestante. Brasília: Editora UnB, 1999.

ATKINSON, D. Towards a philosophical basis for an art of management. In: Proceedings of $2^{\text {nd }}$ Art of Management and Organisation Conference. Paris: ESCP-EAP, 2004.

BENJAMIN, W. 0 surrealismo, o último instantâneo da inteligência européia. In: Textos Escolhidos. São Paulo: Abril Cultural, 1980. (Os Pensadores).

BERGER, P.; LUCKMANN, T. A construção social da realidade. Petrópolis: Vozes, 1988.

BÖHM, S. 'After' the end of art. In: Proceedings of $2^{\text {nd }}$ Critical Management Studies Conference. Manchester: UMIST, 2001. 
BRADLEY, F. Surrealismo. São Paulo: Cosac \&t Naify, 1999.

BRETON, A. Manifestos do Surrealismo. São Paulo: Brasiliense, 1985.

A clara torre. In: Coelho, P. A. (Org.). Surrealismo e Anarquismo. São Paulo: Imaginário, 1990.

BURREL, G. Ciência normal, paradigmas, metáforas e genealogia. In: CLEGG, S. et al. (Orgs.). Handbook de Estudos Organizacionais. v. 1. São Paulo: Atlas, 1999.

BURREL, G.; MORGAN, G. Sociological paradigms and organizational analysis: elements of the sociology of corporate life. London: Heinemann, 1979.

CARR, A. Art as "the great refusal": lessons for organization studies. In: Proceedings of $2^{\text {nd }}$ Art of Management and Organisation Conference. Paris: ESCP-EAP, 2004.

. Art as a form of knowledge: the implications for critical management. TAMARA: Journal of Critical Postmodern Organization Science, v.2, n.1, p.8-30, 2002.

CARR, A.; ZANETTI, L. The emergence of a surrealist movement and its 'estrangement-effect' in organization studies. Human Relations, v.53, n.7, p.891-921, 2000.

CATTANI, I. B. Procedimentos do surrealismo nas artes visuais. In: Ponge, R. (Org.). 0 surrealismo. Porto Alegre: UFRGS, 1991.

COELHO, P. A. (Org.). Surrealismo e Anarquismo. São Paulo: Imaginário, 1990.

FOURNIER, V.; GREY, C. At the critical moment: conditions and prospects for critical management studies. Human Relations, v.53, n.1, p.7-32, 2000.

GOMBRICH, E. H. A História da Arte. Rio de Janeiro: Zahar, 1979.

LÖWY, M. A estrela da manhã: surrealismo e marxismo. Rio de Janeiro: Civilização Brasileira, 2002.

MISOCZKY, M.; ANDRADE, J. Crítica da crítica domesticada nos estudos organizacionais. Revista de Administração Contemporânea, v.9, n.1, p.122-128, 2005.

MISOCZKY, M.; VECCHIO, R. Experimentando pensar: da fábula de Barnard à aventura de outras possibilidades de organizar. Anais do $28^{\circ}$ EnANPAD. Curitiba: ANPAD, 2004.

MORGAN, G. Images of organization. London: Sage, 1986.

Paradigms, metaphors, and puzzle solving in organization theory. Administrative Science Quarterly, v.25, n.4, p.605-622, 1980.

PAULA, A. P. P. de. Tragtenberg revisitado: as inexoráveis harmonias administrativas e a burocracia flexível. Revista de Administração Pública, v. 36, n.1, p.77-81, 2002.

PRESTES MOTTA, F. C. A propósito da "sociedade organizacional". Revista de Administração de Empresas, v.18, n.4, p.71-75, out./dez. 1978.

PIERRE, J. Surrealismo e artes plásticas. In: PONGE, R. (Org.). 0 surrealismo. Porto Alegre: UFRGS, 1991.

RODRIGUES, S.; CARRIERI, A. A tradição anglo-saxônica nos estudos organizacionais brasileiros. Revista de Administração Contemporânea, Edição Especial, p.81-102, 2001.

SCHUSTER, J. 0 sonho e a revolução. In: COELHO, P. A. (Org.). Surrealismo e Anarquismo. São Paulo: Imaginário, 1990.

Surrealismo e Liberdade. In: PONGE, R. (Org.). 0 surrealismo. Porto Alegre: UFRGS, 1991.

SILVA, D. A.; MARRACH, S. A. (Orgs.). Maurício Tragtenberg: uma vida para as ciências humanas. São Paulo: Unesp, 2001.

TRAGTENBERG, M. A delinqüência acadêmica: o poder sem saber e o saber sem poder. São Paulo: Rumo, 1979.

. Burocracia e ideologia. São Paulo: Ática, 1980.

VIEIRA, M.; CALDAS, M. Teoria crítica e pós-modernismo: principais alternativas à hegemonia funcionalista. Revista de Administração de Empresas, v. 46, n.1, p.59-70, 2005.

WOOD JR, T. Organizações espetaculares. Rio de Janeiro: FGV, 2001.

WRIGHT MILLS, C. A imaginação sociológica. 3. ed. Rio de Janeiro: Zahar, 1972. 